\title{
A FORMAÇÃO DE PROFESSORES NA CIDADE DE CATALÃO-GO: \\ UMA ANÁLISE SEMÂNTICO-DISCURSIVA SEGUNDO O \\ SUBSISTEMA DE ATITUDE
}

\author{
TEACHER TRAINING IN THE CITY OF CATALÃO-GO: A \\ SEMANTIC-DISCURSIVE ANALYSIS ACCORDING TO THE \\ ATTITUDE SUBSYSTEM
}

Ingride Chagas Gomes (UFCAT)

ingridecgomes@gmail.com

Lucas Eduardo Marques Santos (UFCAT)

lems.lucas@gmail.com

Fabiola Aparecida Sartin Dutra Parreira Almeida (UFCAT)

fabiolasartin@gmail.com

\begin{abstract}
RESUMO: Este artigo é fruto de um recorte de uma dissertação de mestrado desenvolvida no âmbito dos estudos da linguagem. Dito isso, à luz da Linguística Aplicada difundida no Brasil por Celani (2000) e outros, bem como da Linguística Sistêmico-Funcional elaborada por Halliday (1994), mais especificamente voltada à metafunção interpessoal em seu estrato semântico-discursivo com o Sistema de Avaliatividade e seu subsistema de Atitude produzido por Martin e White (2005), entre outros, o que se buscou foi compreender o discurso construído por professores da rede pública da cidade de Catalão-GO, que não atuam em sua área de formação inicial, porém assumiram a docência em outras áreas do saber. Então, por meio de suas avaliações, mais especificamente, a Apreciação e o Julgamento, foi possível verificar suas impressões sobre as disciplinas em que atuam, percebendo também que estas podem estar associadas às suas experiências, sejam elas positivas ou negativas, vinculadas a terceiros.
\end{abstract}

PALAVRAS-CHAVE: Linguística Aplicada; formação de professores; Avaliatividade; Atitude.

ABSTRACT: This article is the result of an excerpt from a master's dissertation developed in the scope of language studies. That said, in light of Applied Linguistics disseminated in Brazil by Celani (2000) and others, as well as the Systemic-Functional Linguistics developed by Halliday (1994), more specifically focused on the interpersonal metafunction in its semanticdiscursive stratum with the Appraisal System and its Attitude subsystem produced by Martin 
and White (2005), among others, the study sought to understand the discourse constructed by teachers in the public school network of the city of Catalão (in the state of Goiás), who do not work in their area of initial training, but took on the teaching in other areas of knowledge. Therefore, through their evaluations, more specifically, the appreciation and judgment, made it possible to verify their impressions about the subjects they teach, also realizing that these can be associated with their experiences, whether positive or negative, linked to third parties.

KEYWORDS: Applied Linguistics; teacher training; Appraisal; Attitude.

\section{Introdução}

O presente artigo é um recorte de uma pesquisa de mestrado intitulada $O$ subsistema de Atitude no discurso de cinco professoras de Letras que atuam fora da área específica de formação em Catalão-GO e tem como objetivo geral discorrer sobre a formação de professores e apresentar uma análise de Avaliatividade, segundo o subsistema de Atitude com o foco principal na Apreciação, mas considera também secundariamente outras categorias identificadas nos excertos selecionados. Além disso, como objetivos específicos, consideramos (i) traçar um breve panorama sobre a formação de professores no Brasil; (ii) discorrer sobre o arcabouço teórico utilizado; (iii) identificar e analisar os elementos léxicogramaticais avaliativos utilizados pelas professoras ao avaliar as aulas, as disciplinas ministradas e a equipe gestora da escola em que trabalham.

Esta investigação desenvolve-se sob uma perspectiva quantitativa e qualitativa baseada em Dörnyei (2007) e seu Mixed Methods, uma vez que, na visão qualitativa, buscamos compreender esse grupo social e a importância da discussão em torno da formação de professores. Já quanto ao ponto de vista quantitativo, usamos como suporte o programa computacional WordSmith Tools 4.0, que nos auxiliou na contagem, na seleção e influenciou na categorização dos dados.

O corpus acurado para o desenvolvimento da análise apresentada foi coletado a partir de entrevistas realizadas com cinco professoras da rede municipal de educação da cidade de Catalão-GO. Dessa forma, as participantes da pesquisa foram eleitas de acordo com os seguintes critérios: (i) ser professor(a) da Educação Básica; (ii) ser licenciado(a) em Letras Português, ou Português e Inglês; (iii) estar atuando no Ensino Fundamental $-1^{\mathrm{a}}$ e/ou $2^{\mathrm{a}}$ fase ministrando outras disciplinas que não são da sua formação.

Assim, para a coleta de dados, foram realizadas entrevistas semiestruturadas, orientadas através de um questionário composto por dez perguntas. Além disso, outras 
questões pertinentes surgiram no decorrer de cada uma das entrevistas, que foram gravadas pelo aplicativo Gravador de Voz do telefone celular Samsung Galaxy J8 e que depois foram transcritas.

O arcabouço teórico adotado tem sua base firmada na Linguística SistêmicoFuncional, doravante LSF, proposta por Halliday (1994), mais especificamente, o Sistema de Avaliatividade e o subsistema de Atitude, sobretudo no que tange à Apreciação, de acordo com Martin e White (2005), e contempla também autores do campo da Linguística Aplicada, de agora em diante LA, no que diz respeito a pesquisas referentes à formação de professor, como Celani (2000), entre outros, conforme pode-se observar no tópico a seguir.

\section{Linguística Aplicada (LA) e a formação de professores no Brasil}

A LA surgiu durante o período da Segunda Guerra como uma disciplina da Linguística Teórica, tendo a princípio como foco o ensino e a aprendizagem de línguas estrangeiras. Atualmente, ela é caracterizada não mais como uma disciplina, mas sim como uma ciência de caráter inter/transdisciplinar que se preocupa em solucionar problemas que envolvem a linguagem. De acordo com Maria Antonieta Alba Celani, uma das precursoras da LA no Brasil:

Tendo em vista que a linguagem permeia todos os setores de nossa vida social, política, educacional e econômica, uma vez que é construída pelo contexto social e desempenha papel instrumental na construção dos contextos sociais nos quais vivemos, está implícita a importância da LA no equacionamento de problemas de ordem educacional, social, política e até econômica. (CELANI, 2000, p. 20).

Conforme exposto por Celani (2000, p. 20), a LA é uma ciência que se preocupa em solucionar os problemas que envolvem a linguagem e o seu uso em vários contextos, inclusive no contexto educacional. No texto A relevância da Linguística Aplicada na Formulação de uma Política Educacional Brasileira, a autora expõe ainda que a educação é fundamental no Brasil e que a busca de soluções para esse problema é do âmbito da LA.

Assim, ao (re)pensar a LA como uma área autônoma, indica-se uma perspectiva não tradicional e com características específicas que visam investigar as práticas atuais, uma vez que a experiência do mundo capitalista contemporâneo tem tornado mais fluidas, flexíveis e variáveis as relações tanto de poder quanto de conhecimento, tornando a LA atual engajada, como se observa no posicionamento a seguir.

A LA contemporânea visa, portanto, analisar questões concretas da língua em uso

[...] Essencialmente engajada, e portanto intervencionista, visa chegar a propostas 
concretas de "alternativas para o presente" frente a uma época de crise das visões tradicionais de mundo. (MOTTA-ROTH; SELBACH; FLORÊNCIO, 2016, p. 25).

Dessa forma, para Moita Lopes (2009), a LA passa, desde seu surgimento, por alterações, tanto de cunho teórico quanto metodológico, as quais se reestruturam a fim de elaborar novos conceitos que acabam por delinear um novo campo de pesquisa, suas características e particularidades de um trabalho sobre os moldes da LA.

Desse modo, uma educação pública de qualidade é direito de todo cidadão, e, para que tal educação seja fornecida, é necessária a formulação de políticas públicas educacionais por parte do governo que garantam um ensino de qualidade. Além disso, é necessária mão de obra de professor qualificado, já que ele é o mediador do ensino, do conhecimento e o responsável por promover o crescimento intelectual dos alunos. Sabe-se, no entanto, que muitos professores são alocados para ministrarem disciplinas que não são a de sua formação específica, o que pode gerar um grande problema para o ensino e para a aprendizagem.

Sabendo que a LA busca solucionar os problemas encontrados no chamado mundo real, entendemos que os contextos em que a linguagem acontece não têm fronteiras, pois dialogam com outras áreas do saber, que se preocupam com a linguagem em qualquer contexto, não apenas com métodos de ensino e aprendizagem de línguas estrangeiras, como aponta Cavalcanti (1986). Assim, usamos, aliados a esse campo de conhecimento, a vertente teórica propiciada pela Linguística Sistêmico-Funcional proposta por Halliday (1994) e o Sistema de Avaliatividade de Martin e White (2005) para realizar as análises do corpus levantado. A seguir, expomos as leis e as principais políticas educacionais que regem a formação do professor no Brasil.

\subsection{Leis Educacionais e a formação do professor no Brasil}

A Lei de Diretrizes e Bases da Educação, doravante LDB, é a legislação que regulamenta a promoção da educação em nível nacional. Essa lei foi promulgada em 1961; anos depois, em 1996, após passar por uma reforma, foi implantada a nova LDB 9.394/1996. A lei trouxe mudanças positivas para o cenário educacional brasileiro e atualmente vigora uma versão atualizada desta. A LDB divide a educação em dois níveis: a Educação Básica e a Educação Superior, sendo a Educação Básica composta pela Educação Infantil (creche e préescola), pelo Ensino Fundamental $1^{\text {a }}$ (do $1^{\circ}$ ao $5^{\circ}$ ano) e $2^{\text {a }}$ fase (do $6^{\circ}$ ao $9^{\circ}$ ano) e pelo Ensino Médio (do $1^{\circ}$ ao $3^{\circ}$ ano). 
Essa lei afirma que a educação é dever do Estado e da família; ela visa ao pleno desenvolvimento do estudante, preparando-o para o mercado de trabalho e para seu exercício de cidadania. Concernente à formação do professor, a LDB 9.394/1996 estabelece um capítulo para discorrer acerca dos profissionais da educação, quem são estes e quais devem ser suas habilitações.

De acordo com o inciso IV do artigo 61 da LDB 9.394/1996, professores formados em uma área específica poderão atuar ministrando outras disciplinas, quando esses profissionais tiverem "notório saber reconhecido pelos respectivos sistemas de ensino, para ministrar conteúdos de áreas afins à sua formação ou experiência profissional, atestados por titulação específica ou prática de ensino em unidades educacionais da rede pública ou privada [...]”. Porém, muitas vezes, as coisas não funcionam assim: um exemplo disso ocorre quando professores formados em Letras ministram aulas de Matemática, área não afim, o que pode comprometer a promoção da aprendizagem.

Outro documento de suma importância que normatiza a educação brasileira é o Plano Nacional de Educação (PNE). Esse documento determina as diretrizes, metas e estratégias para a política educacional no período de 2014 a 2024. De forma geral, a Lei 13.005/2014, que aprova o PNE, aborda 20 metas, dentre as quais destacamos a meta 15 e a estratégia 15.9, concernentes à formação dos profissionais da educação.

A meta 15 objetiva assegurar que todos os professores tenham formação específica na área de conhecimento em que atuam. Consideramos que essa é uma meta de muita importância para a educação, visto que uma formação específica qualifica o professor para atuar melhor em sala de aula; com isso, eleva-se o nível de qualidade da educação no Brasil. O cumprimento dessa meta caminha em curtos passos, o que pode ser comprovado pela informação divulgada pelo Anuário Brasileiro da Educação Básica ${ }^{1}$.

No dia 25 de junho de 2019, o Plano Nacional de Educação (PNE) completa cinco anos, chegando à metade de seu tempo de vigência. Era esperado que, neste momento, já houvesse um avanço significativo no alcance das metas mais estratégicas para promover avanços na Educação brasileira. O ritmo da trajetória de avanço, porém, está aquém do desejado, como mostra o monitoramento contínuo feito ao longo do período por meio deste Anuário e de sua plataforma irmã, o Observatório do PNE (www.opne.org.br). (CRUZ; MONTEIRO, 2019, p. 8)

Diante disso, pode-se observar que existem políticas educacionais, normas e leis geradas de forma a promover a capacitação dos professores para atuarem de forma qualitativa

\footnotetext{
1 O Anuário da Educação Brasileira tem por objetivo servir "como instrumento de consulta e de acompanhamento da evolução da qualidade da Educação no País” (CRUZ; MONTEIRO, 2019) para professores, pesquisadores e jornalistas. $\mathrm{O}$ anuário contém os dados mais recentes referentes à educação brasileira, constando os seus altos e baixos.
} 
nas disciplinas que ministram. Por exemplo, a Secretaria Estadual de Educação do estado de Goiás tem estabelecido metas de forma a atender a essas demandas. O estado aprovou, no dia 22 de julho de 2015, a Lei 18.969, que estabelece Plano Estadual de Educação (PEE), para o decênio 2015/2025. A lei estabelece metas a serem alcançadas até o ano de 2025, das quais destacamos, a seguir, a meta 17.

\footnotetext{
Meta 17 - Formar, em nível de pós-graduação 50\% (cinquenta por cento) dos professores da Educação Básica, até o último ano de vigência deste PEE, e garantir a todos os profissionais da Educação Básica formação continuada em sua área de atuação, considerando as necessidades, demandas e contextualizações dos sistemas de ensino. (GOIÁS, 2015, p. 40, grifo nosso).
}

Para cumprir com o estabelecido pela meta 17, a Secretaria Municipal de Educação da cidade de Catalão-GO também tem promovido a realização de alguns cursos de formação continuada na cidade. Atualmente, em parceria com a Mosaic Fertilizantes e a Comunidade Educativa de São Paulo (CEDAC), está desenvolvendo o projeto de formação continuada Mosaic Educa Catalão. O objetivo do projeto é proporcionar aos educadores a oportunidade de uma formação de qualidade que acrescente o conhecimento de novas estratégias e possibilidades de trabalho com a leitura.

Tais ações são um fator muito positivo para que o cenário educacional da cidade de Catalão evolua; afinal, os professores são mediadores do ensino e responsáveis por promover o crescimento intelectual dos alunos. Essa responsabilidade está "sobre os ombros do professor", que não deve agir sozinho, mas ser regido por parâmetros e políticas que assegurem uma educação de qualidade.

Contudo, percebemos que, apesar das políticas educacionais, dos planos e das metas estabelecidas nas leis, ainda há brechas que permitem que o professor atue fora de sua área específica de formação, o que pode ser um dos motivos para a existência do grande número de professores ainda deslocados, como pode ser observado a seguir.

\subsection{O Ministério da Educação}

A educação, como processo formador do ensino e da aprendizagem de um cidadão, é direcionada por meio de políticas educacionais. A LDB normatiza que o estabelecimento das políticas educacionais no Brasil cabe ao Ministro da Educação, representante do Ministério da Educação, doravante MEC, e este deve contar com a colaboração do Conselho Nacional de Educação. 
O MEC teve início em 1930, durante o governo de Getúlio Vargas, e, atualmente, tem como área de competência os seguintes assuntos: I - política nacional de educação; II educação infantil; III - educação em geral, compreendendo ensino fundamental, ensino médio, ensino superior, educação de jovens e adultos, educação profissional, educação especial e educação a distância, exceto o ensino militar; IV - avaliação, informação e pesquisa educacional; V - pesquisa e extensão universitária; VI - magistério; e VII - assistência financeira a famílias carentes para a escolarização de seus filhos ou dependentes (MEC, 2014).

Como explicitado anteriormente, muitos professores são alocados para ministrarem disciplinas que não são da sua formação, com a finalidade de complementação de carga horária ou até mesmo devido à falta de um profissional qualificado.

A fim de solucionar problemas decorrentes desse deslocamento, o Ministério da Educação tem criado medidas. São programas para formação inicial e continuada de professores, tais como Formação no Pacto Nacional pela Alfabetização na Idade Certa, ProInfantil, Proinfo Integrado, e-Proinfo, Pró-letramento, Gestar II, Rede Nacional de Formação Continuada de Professores e o Parfor (Plano Nacional de Formação de Professores da Educação Básica), uma ação emergencial que visa estimular a formação em nível superior de professores em exercício nas redes públicas de educação básica, possibilitando o acesso à qualificação profissional exigida pela Educação Nacional.

Apesar da existência desses programas, o problema persiste, porque há muitos professores que ainda se encontram em sala de aula ministrando uma disciplina para a qual não têm formação específica. Infelizmente, o Anuário da Educação Brasileira não apresenta um quadro referente ao número de professores do Ensino Fundamental - $1^{\text {a }}$ fase que se encontram nessa mesma situação, provavelmente, porque a LDB, no Art. 62, abre uma brecha para que professores com qualquer licenciatura atuem na Educação Infantil e na $1^{\text {a }}$ fase do Ensino Fundamental, conforme mostramos a seguir.

Art. 62. A formação de docentes para atuar na educação básica far-se-á em nível superior, em curso de licenciatura plena, admitida, como formação mínima para o exercício do magistério na educação infantil e nos cinco primeiros anos do ensino fundamental, a oferecida em nível médio, na modalidade normal. (BRASIL, 2017, grifo nosso).

É por esse motivo que hoje há um grande número de professores de várias licenciaturas atuando nas séries iniciais da Educação Básica, período de alfabetização e consolidação das bases do conhecimento. Esses docentes acabam ministrando outras disciplinas além daquela para a qual são licenciados. Há professores licenciados em Letras 
ministrando aulas de Matemática, História, Geografia, Ciências, entre outras, o que coloca em questão a qualidade do ensino.

Agora que já discorremos acerca da legislação que rege a educação brasileira e as principais políticas educacionais que regem a formação do professor no Brasil, expomos a seguir um panorama da Linguística Sistêmico-Funcional e suas metafunções, com foco na metafunção interpessoal, em que se encontram o Sistema de Avaliatividade e o subsistema de Atitude, que é utilizado, especificamente, para analisar os dados levantados.

\section{Linguística Sistêmico-Funcional}

A LSF se desenvolveu a partir dos estudos do linguista Michael Halliday. A teoria estuda a língua vinculada a sua inserção social, ao contexto, buscando entender o funcionamento do texto em contexto. De acordo com Fuzer e Cabral (2014, p. 19), a LSF é sistêmica porque vê a língua como redes de sistemas linguísticos interligados, das quais os indivíduos se servem para construir e trocar significados, e ela é funcional porque explica as estruturas gramaticais em relação ao significado, as funções que a linguagem desempenha em textos.

Segundo Halliday (1994), o texto se desenvolve em dois contextos, o contexto de cultura/gênero e o contexto de situação/registro. O contexto de cultura é um contexto macro, está relacionado à forma como as diferentes culturas se utilizam do texto, e o contexto de situação, um contexto micro, está relacionado às variações particulares dentro de cada cultura.

No contexto de situação, há três elementos que determinam as escolhas linguísticas utilizadas pelos falantes/escritores: campo, relações e modo. Eles se relacionam, respectivamente, às metafunções ideacional, interpessoal e textual.

\begin{tabular}{|c|c|}
\hline Contexto de situação & Metafunções da linguagem \\
\hline Campo & Ideacional \\
\hline Relações & Interpessoal \\
\hline Modo & Textual \\
\hline
\end{tabular}

Quadro 1: Relação do contexto de situação e as metafunções da linguagem

Fonte: adaptado de Almeida (2010, p. 19)

O campo se realiza por meio da metafunção ideacional; trata-se da expressão das ideias, da possibilidade de falar sobre o mundo; observa-se quem fala, com quem, onde, porquê e em que sentido. As relações se realizam por meio da metafunção interpessoal; trata- 
se da interação entre as pessoas, da troca de informações entre falante e ouvinte, escritor e leitor. O modo, seja ele escrito ou falado, se realiza através da metafunção textual, que organiza a estrutura do texto (ALMEIDA, 2010).

A seguir, apresentamos os conceitos principais de um dos sistemas semânticodiscursivos utilizado neste artigo para realizar análises dos dados selecionados, o Sistema de Avaliatividade.

\subsection{O sistema semântico-discursivo de Avaliatividade (Appraisal)}

A área voltada aos estudos linguísticos busca entender, desde que os seres humanos começaram a viver em comunidade, a necessidade das relações comunicativas e os desdobramentos advindos desse contato social que organiza as estruturas sociais do mundo em que vivemos, ou seja, é por meio da língua que são elaborados e/ou propagados (ou não) determinados discursos. Por isso, circula, entre os estudiosos da Avaliatividade, a compreensão de que há um certo grau de entendimento sobre o que se diz e para quem se diz algo ou alguma coisa, pois se relaciona "com a presença subjetiva de escritores/oradores em textos, à medida que eles adotam posturas tanto em relação ao material que apresentam, quanto àqueles com quem se comunicam" (MARTIN; WHITE, 2005, p. 1, apud MARQUESSANTOS, 2019, p. 92) ${ }^{2}$.

Assim, sob uma visão teórica sistêmico-funcional, surge o estudo da Appraisal (termo em língua inglesa), formulada por Martin e White (2005), que no Brasil tornou-se Avaliatividade, segundo Vian Jr. (2009). Esse termo foi escolhido em detrimento do conceito elaborado por Labov, que se volta à avaliação (evaluation), assim o próprio autor aponta:

\footnotetext{
Nos casos dos termos apreciação ou valoração, há vários motivos para recusá-los. No caso de apreciação, por ser o melhor correspondente a appreciation, um dos três subsistemas de Atitude. Quanto à valoração, tem, primariamente, o sentido de 'atribuir valor a algo', o que reduz significativamente o escopo envolvido na avaliação, uma vez que, juntamente ao valor, agregam-se crenças, emoções, afeto, relações sociais e tantos outros aspectos; e ainda pelo fato de, no subsistema de apreciação, haver o termo inglês valuation, que, em determinados casos, também poderia ser traduzido por valoração. [...] O sentido do appraisal system [...] vai muito além de valoração, por isso a sugestão do termo Sistema de Avaliatividade, uma vez que estamos considerando um potencial de significados avaliativos disponíveis no sistema linguístico. (VIAN JR., 2009, p. 102-103).
}

\footnotetext{
${ }^{2}$ No original: "[...] with the subjective presence of writers/speakers in texts as they adopt stances towards both the material they present and those with whom they communicate" (MARTIN; WHITE, 2005, p. 1).
} 
A Avaliatividade, enquanto sistema, sugere um recurso comunicativo baseado em uma perspectiva dialógica que segue os princípios da intencionalidade, da subjetividade do indivíduo e de suas escolhas léxico-gramaticais na elaboração do texto em seu discurso.

Estas avaliações atitudinais [...] revelam os sentimentos e valores do orador/escritor, mas também [...] sua expressão pode estar relacionada ao status ou autoridade do orador/escritor como interpretado pelo texto e porque eles operam retoricamente para construir relações de alinhamento e relacionamento entre o escritor/orador e entrevistados reais ou potenciais (MARTIN; WHITE, 2005, p. 2, apud MARQUESSANTOS, 2019, p. 93 $)^{3}$.

O falante/escritor expressa assim suas emoções, suas ideias, seu ponto de vista, suas aprovações ou reprovações quanto a algo, alguém ou alguma coisa, o que indica seu lugar na sociedade e o constitui como ator social, ou seja, sua identidade autoral, como indicam os autores acima citados. Já para Ngo e Unsworth (2015, p. 1), esse sistema se associa às questões voltadas às respostas de solidariedade, pois

A capacidade de expressar os sentimentos e opiniões pessoais com precisão e sofisticação em contextos apropriados tem sido uma das questões mais importantes no ensino e pesquisa de idiomas. Através da expressão de seus sentimentos e opiniões, pode-se construir um tipo particular de relacionamento com o leitor/ouvinte, confirmando a solidariedade com seus pontos de vista ou conduzindoos, ou persuadindo-os a um certo ponto de vista e ajustando o nível de certeza nas declarações. (NGO; UNSWORTH, 2015, p. 1, apud MARQUES-SANTOS, 2019, p. $93)^{4}$.

Sob o ponto de vista sistêmico-funcional uma determinada produção textual é atravessada pelo conceito de dialogismo de fundamentação bakhtiniana, pois a LSF entende as relações discursivas da linguagem como concretas e que são formadas a partir da interpessoalidade tendo como resultado a produção de enunciados individuais ou coletivos.

A realidade atual da linguagem-discurso não é o sistema abstrato das formas linguísticas, não o enunciado monológico isolado, e não o ato psicológico de sua implementação, mas o evento social da interação verbal implementado em um enunciado ou enunciados. (MARTIN; WHITE, 2005, p. 92, apud MARQUESSANTOS, 2019, p. 94) ${ }^{5}$.

\footnotetext{
${ }^{3}$ No original: "These attitudinal evaluations [...] reveal the speaker's/writer's feelings and values but also [...] their expression can be related to the speaker's/writer's status or authority as construed by the text, and because they operate rhetorically to construct relations of alignment and rapport between the writer/speaker and actual or potential respondents" (MARTIN; WHITE, 2005, p. 2).

${ }^{4}$ No original: "The capacity to express one's personal feelings and opinions with precision and sophistication in appropriate contexts has been one of the very important issues in language teaching and research. Through expressing one's feelings and opinions, one can build a particular kind of relationship with the reader/hearer by confirming solidarity with their views or by leading or persuading them towards a certain viewpoint and by finetuning the level of certainty in statements" (NGO; UNSWORTH, 2015, p. 1).

${ }^{5}$ No original: "The actual reality of language-speech is not the abstract system of linguistic forms, not the isolated monologic utterance, and not the psychological act of its implementation, but the social event of verbal interaction implemented in an utterance or utterances" (MARTIN; WHITE, 2005, p. 92).
} 
Essa realidade compreende, ainda, o posicionamento dos indivíduos em que os significados se encontram diluídos nas vozes textuais do falante/escritor, sendo expostos léxico-gramaticalmente, o que o constitui como parte integrante de um modelo holístico de linguagem e de contexto social (MARTIN; WHITE, 2005). No delinear da interpessoalidade, segundo os autores acima citados, surgem três subsistemas que estruturam os atos de comunicação e de fala. São eles: o Engajamento, a Gradação e a Atitude. Este último, descrevemos na próxima seção.

\subsubsection{O subsistema interpessoal de Atitude}

O subsistema de Atitude se constitui pela projeção semântico-discursiva de enunciados que se vinculam "a emoção, a ética e a estética", apontados por Martin e White (2005, p. 42, apud MARQUES-SANTOS, 2019, p. 96). Nesse sentido, a emoção surge como um recurso fisiológico de expressão que acompanha o indivíduo desde o nascimento e em que os seres humanos buscam representar e/ou exteriorizar seus sentimentos, sejam eles estabelecidos por motivação social (exterior) ou individual (interior), e que, segundo a Atitude, é denominada de Afeto. É nessa categoria que os sentimentos são registrados de acordo com a polaridade envolvida na expressão dialógica, sendo ela positiva ou negativa.

Ainda, ao lidar com acontecimentos voltados ao comportamento, seja do próprio ser ou o que o falante/escritor profere acerca do outro, para esse subsistema, o que há é um tipo de Julgamento, podendo ser este dividido em duas grandes categorias: a estima social, que envolve argumentos voltados para a relação moral do indivíduo, e a sanção social, que é projetada a partir de uma implicação legal.

Dito isso, a Apreciação está associada aos princípios relacionados às "semioses ou fenômenos naturais" (MARTIN; WHITE, 2005, p. 43, apud MARQUES-SANTOS, 2019, p. 97). Assim, os autores indicam a formação desse recurso semântico-discursivo, por meio de suas categorias e subcategorias, sendo elas: reação, composição e valoração.

Quando se trata de reação, Almeida (2010, p. 58) aponta que esta "corresponde às reações que as coisas provocam nas pessoas (outros), isto é, como as coisas captam a atenção das pessoas". Pode, portanto, se subdividir em reação-impacto e reação-qualidade, que, respectivamente, são as impressões que se tem sobre determinadas 'coisas' e como elas afetam o falante, que tende a emitir algum tipo de parecer promovendo certas avaliações em seu discurso; já quando o indivíduo expressa o nível de satisfação, ele avalia a qualidade do que lhe está sendo exposto. 
A segunda categoria da Apreciação é denominada composição, pois são "os sentimentos que dizem respeito à organização, à elaboração, e à forma pela qual as coisas e objetos foram construídos ou elaborados" (ALMEIDA, 2010, p. 110). A composição, por conseguinte, abrange elementos léxico-gramaticais que, em seu cerne, estão vinculados à elaboração de avaliações sobre as propriedades subordinadas à proporcionalidade e à complexidade das 'coisas'. Por esse motivo, também se encontra sub-categorizada por Martin e White (2005) entre equilíbrio e complexidade.

A terceira e última categoria que integra a Apreciação é a valoração, que "tem a ver com a nossa avaliação da significação social do texto/processo. [...] corresponde ao valor que se atribui às coisas ou objetos" (ALMEIDA, 2010, p. 60). Em síntese, os três itens que formam esse subsistema têm uma carga interpessoal que permeia todos os níveis de constituição dos discursos (HALLIDAY, 1979). Portanto, na seção abaixo, apresentamos análises que buscam discutir a formação de professores na cidade de Catalão, por meio da Apreciação inerente nos discursos dos professores entrevistados, verificando o aparecimento das classificações que compõem esse recurso da Atitude.

\section{Análise do corpus: a Apreciação das aulas e das disciplinas e avaliações de terceiros ${ }^{6}$}

Essa categoria contempla as avaliações realizadas pelas professoras sobre as aulas e as disciplinas ministradas (avaliações do tipo Apreciação), sobre a equipe gestora da escola em que trabalham (avaliações de estima social do tipo Julgamento) e também contempla algumas autoavaliações de Afeto e de Julgamento.

Excerto 1: Professora 3: Eu acho que gera no aluno um desinteresse (Reaçãoimpacto -), e na educação, eu acredito que gera um aprendizado mais fraco (Composição-complexidade -).

Sobre a pergunta "Qual o impacto que a atuação fora da zona de conforto gera na educação?", os itens destacados da resposta dada pela professora realizam uma avaliação de Apreciação reação-impacto negativa e uma avaliação de Apreciação reação-qualidade negativa. Primeiro, ela utiliza o processo mental cognitivo "acho" para marcar a dúvida no seu posicionamento avaliativo, expressando não ter certeza se é a atuação fora da zona de

\footnotetext{
${ }^{6}$ Embora não seja o foco dessa macrocategoria, alguns excertos analisados, além da Apreciação, sejam das aulas ou das disciplinas ministradas, e além da Atitude de Julgamento com relação à equipe gestora ou à figura do professor, apresentam autoavaliações do tipo Afeto e Julgamento. Achamos por bem não fazer um recorte dos excertos para que se encaixassem em suas macrocategorias, a fim de não se perder o sentido expresso pelo contexto geral de cada excerto.
} 
conforto que "gera" (processo material criativo) o "desinteresse" (atributo) no aluno, mas, através do processo mental cognitivo "acredito", ela expressa a crença de que o aprendizado é "mais" (intensificador) "fraco" (epíteto), marcando uma avaliação de Apreciação por composição-complexidade negativa.

Excerto 2: Professora 4: eu tenho uma boa (Reação-qualidade +) interação com os alunos do $6^{\circ}$ ano, porque eles foram meus alunos no $5^{\circ}$ ano.

A professora 4 expressa, no excerto acima, uma avaliação explícita de Apreciação positiva do tipo reação-qualidade, caracterizando a interação com os alunos através do uso do epíteto "boa".

Excerto 3: Professora 1: Mas eu acho que as outras que é leitura, que é a parte de, acaba sendo a parte da linguagem também, História, Geografia, é, não tem dificuldade (Julg: Capacidade +).

Nesse excerto, a Professora 1 realiza uma avaliação de Julgamento do tipo capacidade positiva, utilizando o processo mental de cognição "acho", o adjunto modal de polaridade negativa "não”, associado ao processo relacional "ter" e ao epíteto "dificuldade”, que, nesse contexto, tem uma prosódia semântica positiva, visto que não ter dificuldade é um fator positivo. Acreditamos que isso ocorre porque ela está se referindo às disciplinas que trabalham com a leitura e com a interpretação de textos, História e Geografia, ou seja, áreas afins com a área de formação da professora, área de Ciências Humanas.

Excerto 4: Professora 3: Boas, eu acho (Reação-qualidade +). Mas assim eu tenho uma turma que... eu tenho uma turma boa (Valoração +), né? É o que eu falo, às vezes se essa entrevista tivesse sido feita há uns 2 ou 3 anos atrás eu falaria assim "nossa, horríveis" (Reação-qualidade -).

Percebe-se, nesse excerto, que a relação de positividade/negatividade está relacionada à experiência profissional da professora e ao público com o qual ela trabalha. Ao falar sobre o início da docência, em decorrência da falta de experiência, ela realiza uma avaliação de Apreciação do tipo reação-qualidade negativa, pois utiliza o atributo "horriveis" para marcar a avaliação realizada concernente às aulas ministradas; sobre hoje, após dois anos em sala de aula, ela expressa uma avaliação de Apreciação tipo reação-qualidade positiva através do atributo "boas" para caracterizar as aulas. Ela realiza também uma avaliação de Apreciação do tipo valoração da turma com a qual trabalha utilizando o atributo "boa", também positiva.

Excerto 5: Professora 5: [...] eu acho que História é a disciplina mais difícil (Composição-complexidade -) de ensinar pra os alunos dessa faixa etária. 
No excerto (5), a Professora 5 realiza uma avaliação de Apreciação do tipo composição-complexidade negativa da disciplina História através do uso do processo mental cognitivo "acho", do intensificador "mais" e do epíteto "dificil”, demonstrando o grau de complexidade da disciplina História para essa professora em questão.

Excerto 6: Professora 4: [...] eu creio que seria mais eficaz (Reação-qualidade +) cada um trabalhar na sua área de formação como eu te falei é diferente (Composição-complexidade -), são diferentes (Composição-complexidade -) as aulas, né?

Nesse excerto, a Professora 4 realiza uma avaliação de Apreciação de reaçãoqualidade positiva sobre cada profissional trabalhar na sua área de formação, utilizando o processo mental cognitivo "creio", o intensificador "mais" e o atributo "eficaz”. Através do epíteto "diferente", a docente realiza uma avaliação de Apreciação do tipo composiçãocomplexidade para se referir às aulas.

Excerto 7: Professora 4: [...] neste ano, 2019, as turmas com as quais eu trabalho são bem intensas, intensas, ativas [...] (Valoração +).

No excerto acima apresentado, há uma avaliação de Apreciação de valoração positiva realizada pelo intensificador "bem" e os atributos "intensas" e "ativas" para avaliar as turmas.

Excerto 8: Professora 4: [...] eu creio que a participação dos alunos, ela é muito importante (Valoração +).

Nota-se, acima, que há uma avaliação de Apreciação do tipo valoração positiva da participação dos alunos em sala de aula, centrada no uso do processo mental cognitivo "creio", do processo relacional "é”, do intensificador "muito" e do epíteto "importante" ao avaliar a participação dos alunos.

Excerto 9: Professora 5: Eu sou privilegiada, (Julg: Tenacidade + ) porque eu tenho uma turminha que é um encanto (Julg: Normalidade +), né? Minha turma é muito dedicada muito esforçada (Julg: Capacidade +).

No excerto (9), a Professora 5 realiza uma autoavaliação de Julgamento do tipo tenacidade através do atributo "privilegiada" e realiza avaliações de Julgamento do tipo normalidade positiva através do uso do atributo "encanto" associado ao intensificador “muito", utilizado duas vezes, e, ainda, dos atributos "esforçada” e "dedicada", que foram utilizados para avaliar a turma com a qual trabalha atualmente, por meio de um Julgamento de capacidade positiva. 
Excerto 10: Professora 2: Olha, não, aqui nessa escola são excelentes (Valoração +) os trabalhos, né? [...] nós fazemos o planejamento, aqui se trabalha em equipe, não trabalha assim, por exemplo, são quatro $2^{\circ}$ anos, eu tô no $2^{\circ}$, então são quatro $2^{\circ}$ anos, o planejamento é o mesmo que uma dá outra dá e assim se trabalha em equipe, e coordenadora sempre junto, sempre sabe dando ponto de vista e é muito bom (Reação-qualidade +) eu tô gostando (Felicidade +), são excelentes (Julg: Capacidade +) aqui as coordenadoras.

A Professora 2, no excerto (10), realiza uma avaliação positiva de Apreciação do tipo valoração, realizada através do processo relacional "são" associado ao epíteto "excelentes", termo utilizado para apreciar os trabalhos realizados pelas coordenadoras, que, mais do que bons, são excelentes.

A docente utiliza o processo relacional " $e$ ", o intensificador "muito" e o atributo "bom” para realizar uma Apreciação intensificada do tipo reação-qualidade e expressar o quão positivo é o papel da coordenação frente ao planejamento, o quanto é bom para um professor receber o apoio da coordenação, o ponto de vista delas. E, com relação às coordenadoras, a professora realiza uma avaliação de Julgamento de capacidade positiva utilizando o atributo "excelentes" para caracterizá-las.

\section{Considerações finais}

Constatamos, por um lado, que as avaliações de Apreciação externadas pelas professoras são positivas, quando elas avaliam a profissão, sua interação com os alunos e a participação dos alunos em sala de aula. Por outro lado, são negativas, quando as docentes avaliam o impacto que a atuação do professor fora da sua área específica gera na educação e no aprendizado dos alunos, ou seja, elas reconhecem que há um impacto negativo.

Em relação às aulas, as professoras, em suas avaliações, realizam um paralelo entre o passado e o presente, avaliam negativamente as aulas ministradas no passado e positivamente as aulas que ministram no presente, fator que é influenciado pelas experiências adquiridas em sala de aula com o passar do tempo. Quanto às avaliações de Julgamento de terceiros, as professoras sempre externam avaliações positivas acerca das coordenadoras e das turmas com as quais trabalham, evidenciando o bom relacionamento que há entre eles.

Este estudo nos revela, a partir das análises, avaliações positivas e negativas, por parte das professoras, concernentes à situação de deslocamento, indicando, por meio da avaliação, que as docentes, em sua maioria, demonstram preferência por atuarem dentro de sua área de formação, área para a qual são capacitadas e com a qual têm uma maior afinidade e domínio. 


\section{REFERÊNCIAS}

ALMEIDA, F. A. S. D. P. Os elementos de Atitude no discurso do professor: um exercício em Análise do Discurso Sistêmico-Funcional. São Carlos: Pedro \& João Editores, 2010.

BRASIL. Lei de diretrizes e bases da educação nacional. - Brasília: Senado Federal, Coordenação de Edições Técnicas, 2017. 58 p. Disponível em:

http://www2.senado.leg.br/bdsf/bitstream/handle/id/529732/lei_de_diretrizes_e_bases_1ed.pd f. Acesso em: 26 jun. 2019.

BRASIL. LEI N 9.394, DE 20 DE DEZEMBRO DE 1996. - Brasília: Senado Federal, Disponível em: http://www.planalto.gov.br/Ccivil_03/leis/L9394.htm. Acesso em: 28 fev. 2021.

BRASIL. LEI N $N^{o}$ 13.005, DE 25 DE JUNHO DE 2014. - Brasília: Senado Federal, Disponível em: http://www.planalto.gov.br/ccivil_03/_ato2011-2014/2014/lei/113005.htm. Acesso em: 24 jun. 2021.

CAVALCANTI, M. C. A propósito de linguística aplicada. Trabalhos em Linguística Aplicada, Campinas, v. 7, p. 5-12, 1986.

CELANI, M. A. A. A Relevância da Linguística Aplicada na Formulação de uma Política Educacional Brasileira. In: FORTKAMP, M. B. M.; TOMICH, L. M. B. (Orgs.). Estudos em Homenagem ao Professor Hilário Inácio Bohn. Florianópolis, SC: Insular, 2000.

CRUZ, P.; MONTEIRO, L. (Org.) Anuário Brasileiro da Educação Básica, 2019. São Paulo: Editora Moderna. Disponível em:

https://www.todospelaeducacao.org.br/_uploads/_posts/302.pdf. Acesso em: 24 jun. 2021.

DÖRNYEI, Z. Quantitative, Qualitative And Mixed Methods Research. In: DÖRNYEI, Z. Research Methods In Applied Linguistics. Oxford: Oxford University Press, 2007. p. 24-47.

FUZER, C. CABRAL, S. R. S. Introdução à gramática sistêmico-funcional em língua portuguesa. 1. ed. Campinas, São Paulo: Mercado das Letras, 2014.

GOIÁS. LEI No 18.969, DE 22 DE JULHO DE 2015. 2015. Goiânia. Disponível em: https://portaleduca.educacao.go.gov.br/wp-content/uploads/dlm uploads/2019/02/PLANOESTADUAL-DE-EDUCA\%C3\%87\%C3\%83O-PEE-2015-2025-1.pdf. Acesso em: 26 jun. 2021.

HALLIDAY, M. A. K. Modes of meaning and modes of expression: types of grammatical structure and their determination by different semantic functions. In: ALLERTON, D. J.; CARNEY, E.; ADDCROFT, D. (Eds). Function and context in linguistic analysis. Cambridge: Cambridge University Press, 1979. p. 57-79.

HALLIDAY, M. A. K. Introduction to functional grammar. 2. ed. London: Arnold, 1994. 
MARQUES-SANTOS, L. E. AVALIATIVIDADE EM DISCURSOS DE SURDOS NO ENSINO MÉDIO: Uma Análise Sistêmico-Funcional. 2019. 226 f. Dissertação (Mestrado em Estudos da Linguagem) - Unidade Acadêmica Especial de Letras e Linguística, Universidade Federal de Goiás-Regional Catalão, Catalão, 2019.

MARTIN, J. R.; WHITE, P. The language of evaluation: appraisal in English. New York: Palgrave, 2005.

MEC. História. 2014. Brasília. Disponível em:

http://portal.mec.gov.br/index.php?option=com_content\&view=article\&id=2\&Itemid=1175. Acesso em: 26 jun. 2019.

MOITA LOPES, L. P. Da aplicação de linguística à linguística aplicada indisciplinar. In: PEREIRA, R. C.; ROCA, P. (Orgs.). Linguística Aplicada: um caminho com diferentes acessos. São Paulo: Contexto, 2009. p. 11-24.

MOTTA-ROTH, D.; SELBACH, H. V.; FLORÊNCIO, J. A. Conversações indisciplinares na linguística aplicada brasileira entre 2005-2015. In: JORDÃO, C. M. (Org.). A Linguística Aplicada no Brasil: rumos e passagens. Campinas: Pontes Editores, 2016. p. 17-57.

NGO, T.; UNSWORTH, L. Reworking the Appraisal framework in ESL research: refining attitude resources. Functional Linguistics, Suíça, v. 2, n. 1, p. 2-24, 2015.

VIAN JR, O. O sistema de avaliatividade e a linguagem da avaliação. In: VIAN JR., O; SOUZA, A. A de; ALMEIDA, F. S. D. P. A linguagem da avaliação em língua portuguesa. Estudos sistêmico-funcionais com base no Sistema de Avaliatividade. São Carlos: Pedro \& João Escritores, 2010. p. 1-40. 